\title{
CONTINUOUS LIDAR OBSERVATION OF NEAR SURFACE AEROSOL USING OPTICAL AND SAMPLING DATA FROM GROUND-BASED INSTRUMENTS
}

\author{
Jamrud Aminuddin ${ }^{1}$, Ilham Alimuddin ${ }^{3}$, Laras Tursilowati ${ }^{4}$, Naohiro Manago ${ }^{5}$, and Hiroaki Kuze ${ }^{2}$ \\ ${ }^{l}$ Department of Physics, Faculty of Mathematics and Natural Science, Universitas Jenderal Soedirman, \\ Jl. dr. Suparno 61 Karangwangkal-Purwokerto, Jawa Tengah, 53123, Indonesia. \\ ${ }^{2}$ Center for Environmental Remote Sensing, Chiba University, \\ 1-33 Yayoi-Cho, Inage-Ku, Chiba, 2630043, Japan \\ ${ }^{3}$ Department of Geology, Faculty of Engineering, Universitas Hasanuddin, \\ Jl. Perintis Kemerdekaan km 10, Makassar, Sulawesi Selatan, 90245, Indonesia. \\ ${ }^{4}$ Space Science Center, Indonesian Institute of Aeronautics and Space (LAPAN), \\ Jl. Dr. Djunjunan No.133, Bandung, Jawa Barat, 40173, Indonesia. \\ ${ }^{5}$ Institute of Space and Astronautic Science, Japan Aerospace Exploration Agency, \\ 3-1-1 Yoshinodai, Chuo-Ku, Sagamihara, Kanagawa, 2525210, Japan. \\ *Email: jamrud.aminuddin@unsoed.ac.id
}

\begin{abstract}
Monitoring of near-surface aerosol is important for both public health issues and radiation budget studies. In this study, we report a continuous observation method of aerosol particles by means of a vertical Mie-scattering lidar in combination with other optical and sampling instruments operated at the ground level. In the Fernald method used for processing the lidar signal, the most appropriate value of lidar ratio at $532 \mathrm{~nm}$ is estimated from the Mie-scattering calculation. The input parameters, namely, the mode radius, variance, and both real and imaginary parts of refractive index, are so determined as to reproduce the data from ground-based sampling instruments. Instead of the far-end boundary condition, the extinction coefficient at the surface level is used for constraining the retrieved aerosol extinction profile. The correction of the truncation and relative humidity $(\mathrm{RH})$ effects on the scattering data from the sampling is made with the help of the optical data from a visibility-meter. We discuss the observed features in both low and high RH cases. Such a capability will be useful for uninterrupted lidar observations of near-surface aerosols irrespective of the presence of clouds that often hinders signal observations at higher altitudes where the aerosol-free atmosphere is assumed for the conventional Fernald analysis.
\end{abstract}

\section{INTRODUCTION}

The effects of atmospheric aerosols have been discussed in the context of both public health and the Earth's radiation budget in relation to global climate change [1]. Since most of the sources and sinks are located on the ground, the precise monitoring of aerosol behavior near the surface level is indispensable for better understanding of aerosol characteristics. Mie-scattering lidars have provided a valuable tool for studying aerosol profiles as well as the aerosol-cloud interaction. The problem in the conventional analysis based on the Fernald method [2] is that first, the value of lidar ratio $\left(S_{1}\right)$ has to be assumed, and second, lidar signals at the far-end boundary is needed so that the analysis can be started at the nearly aerosol-free altitude, $5 \sim 6 \mathrm{~km}$ above the surface. Occasionally in the lower troposphere, the high variability of aerosol property leads to the substantial change in the lidar ratio. Besides, the presence of lower clouds often makes it impossible to observe lidar signals at higher altitudes. These problems can potentially be solved by combining the lidar data with sampling and optical data from instruments continuously operated in the observatory where the lidar setup is installed [3], [4].

Various remote sensing instruments and aerosol sampling instruments have routinely operated at the Center for Environmental Remote Sensing (CEReS), Chiba University to study the detailed properties of urban aerosol [5]-[7]. In the 
present paper, we report on the analysis of the data from a vertical lidar with ancillary information on aerosol observed with an integrating nephelometer (scattering coefficient), an aethalometer (absorption coefficient), and an optical particle counter (size distribution). The extinction coefficient obtained from these sampling data is compared with the in-situ optical data from a visibility-meter in order to carry out the truncation and relative humidity (RH) corrections of the sampling data [8], [9]. Then the Mie-scattering calculation is implemented to reproduce the observed aerosol properties at the surface level, and this provides us with the value of $S_{1}$ as well.

\section{METHODOLOGY}

\subsection{Sampling instruments and Mie-scattering calculation}

Near-surface values of aerosol extinction coefficient (AEC) are obtained from the groundbased sampling instruments. An integrating nephelometer (TSI 3563) provides the scattering coefficient measured at the three wavelengths of 450, 550, and $700 \mathrm{~nm}$. An aethalometer (Magee, AE31) measures the values of black carbon (BC) concentration at the seven wavelengths $(370,470$, $520,590,660,880$, and $950 \mathrm{~nm})$. Then, the temporal change of AEC at the lidar wavelength $(532 \mathrm{~nm})$ is calculated by carrying out the interpolation based on the Angstrom exponent [6]. The value of lidar ratio can be estimated by means of the Mie-scattering calculation using aerosol parameters of the mode radius, variance, and the real and imaginary parts of refractive index. The mode radius and variance can be directly obtained from the record of a particle counter (Rion, KC22B). The values of refractive index are estimated from the condition that the observed wavelength dependence of both AEC and absorption coefficient is reproduced [6], [7].

\subsection{Optical measurement}

The in-situ, optical data on the ambient aerosol is obtained using a visibility-meter (Vaisala, PWD 52). This instrument yields the value of meteorological visibility, $V$, every $10 \mathrm{~min}$. The AEC value at $550 \mathrm{~nm}, \alpha_{e x t}$, is obtained using the Köschmeider equation of $\alpha_{e x i}=\ln (20) / V$ - $\alpha_{\text {Ray }}$ [6], where $\alpha_{\text {Ray }}$ is the extinction due to the Rayleigh scattering of air molecules [10].

\subsection{Truncation and RH corrections}

Normally the scattering coefficient derived from the nephelometer is smaller than the ambient value because of the truncation error [8]. The causes of this error are first, the loss of larger particles in the sampling process, and second, the limited angular coverage $\left(7^{\circ}\right.$ to $\left.170^{\circ}\right)$ of the scattering measurement. We employ the AEC value from the visibility-meter to carry out the correction of this error. When the ambient $\mathrm{RH}$ is high ( $>\sim 50 \%$ ), an additional correction of $f(R H)$ is applied to consider the RH difference between the ambient (wet) and instrumental (dry) conditions. Here $f(R H)$ stands for the ratio of aerosol scattering cross-sections between the ambient and dry conditions [9].

\subsection{Lidar system and Fernald analysis}

In the present work, we use the $532 \mathrm{~nm}$ lidar data of the National Institute for Environmental Studies (NIES) lidar [11] operated on the campus of Chiba University. The vertical profile of AEC can be obtained every 15 min by analyzing the data using the Fernald analysis. In this analysis, the lidar ratio for air molecules $\left(S_{2}\right)$ is fixed at $8.52 \mathrm{sr}$, whereas the parameter for aerosol $\left(S_{1}\right)$ is determined through the Mie scattering calculation as mentioned above. Instead of the far-end boundary, near surface values of AEC is obtained from the ground-based instruments to constraint the derived profile of AEC.

\section{RESULTS AND DISCUSSION}

Figures 1(a) and (b) show the temporal change of AEC at $550 \mathrm{~nm}$ recorded during March 19-20 and May 19-21, 2017, respectively, exemplifying the lower and higher RH cases. It is seen that in both cases, the original, sampling-based AEC value is notably small as compared with the optically (visibility-meter) measured value. In the low RH case (with minimum RH of $\sim 20 \%$ ) of Fig. 1(a), the AEC value after correcting the truncation error is in good agreement with the ambient value. In the high $\mathrm{RH}$ case (with minimum $\mathrm{RH}$ of $\sim 60 \%$ ) in Fig. 1(b), on the other hand, 
deviations are seen between the sampling and optical data when only the truncation correction is applied. A better agreement can be seen after further applying the $f(R H)$ correction.
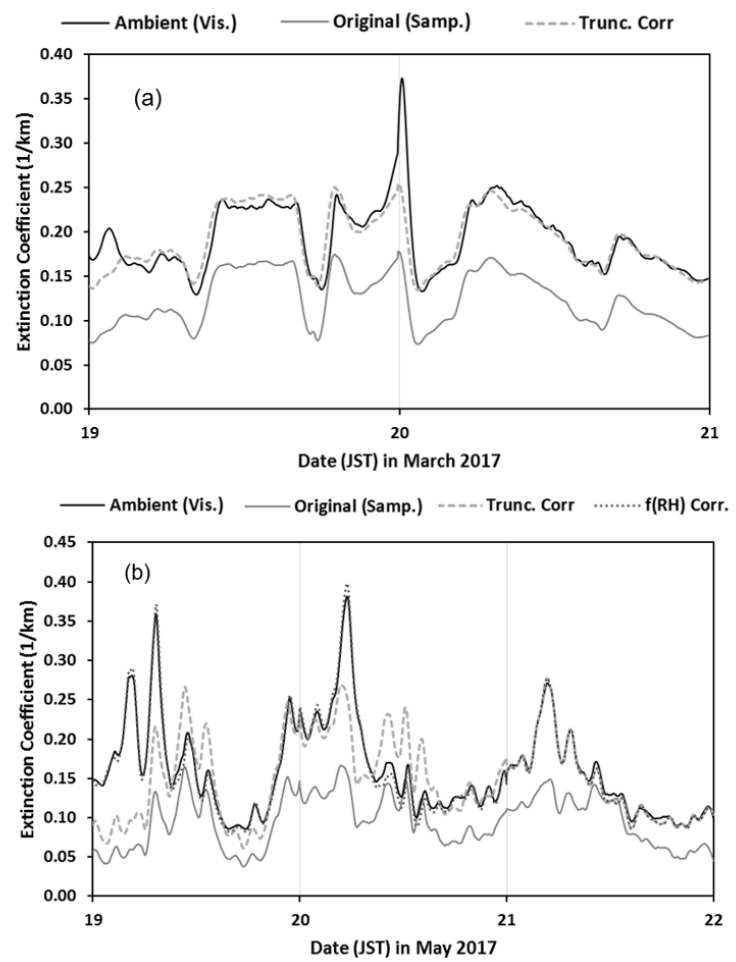

Fig. 1 Temporal change of AEC observed under a relatively (a) low $\mathrm{RH}$ and (b) high $\mathrm{RH}$ conditions. In (b), both the truncation and $f(R H)$ corrections are applied to the value from the sampling measurement.

Figure 2 shows an example of Mie calculation applied to the data from sampling instruments. The size distribution measured with the optical particle counter is fitted as shown in Fig. 2(a). The wavelength dependence of the normalized scattering coefficient and absorption coefficient is plotted in Fig. 2(b) and (c), respectively. The single scattering albedo is plotted in Fig. 2(d). The resulting Mie-scattering parameters for this case (10:00 JST on March 20, 2017) are as follows: mode radius $=0.0268 \mu \mathrm{m}$, variance $=0.3323$, and refractive index $=1.593-0.023 i$. Since the scattering phase function $f(\theta)$ is readily obtained from the Mie calculation, the value of $S_{1}$ can be derived as the value of $f(\pi)^{-1}$.
Figures 3(a) and (b) show the temporal change of lidar ratio at $550 \mathrm{~nm}$ for the case of relatively low and high RH case, respectively. Then, the lidar ratio is employed in the Fernald analysis for retrieving the AEC profiles from the NIES lidar data.
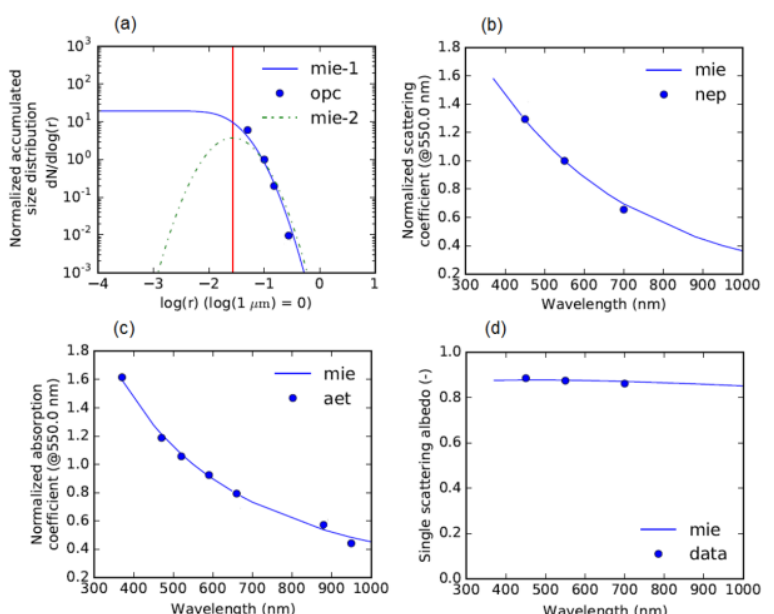

Fig. 2 Fitting of observed aerosol parameters with Mie scattering calculation for the case of data observed at 10:00 JST on March 20, 2017.

(a)

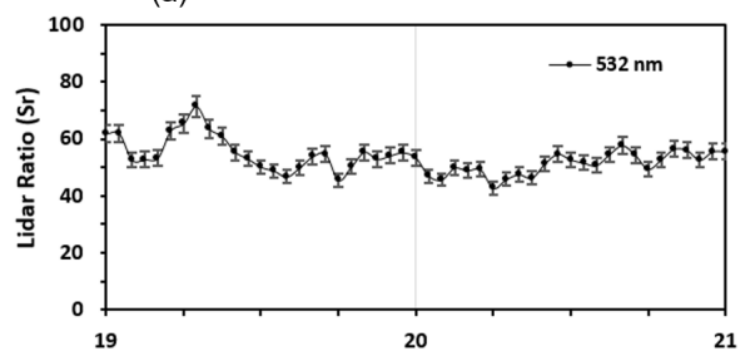

(b)

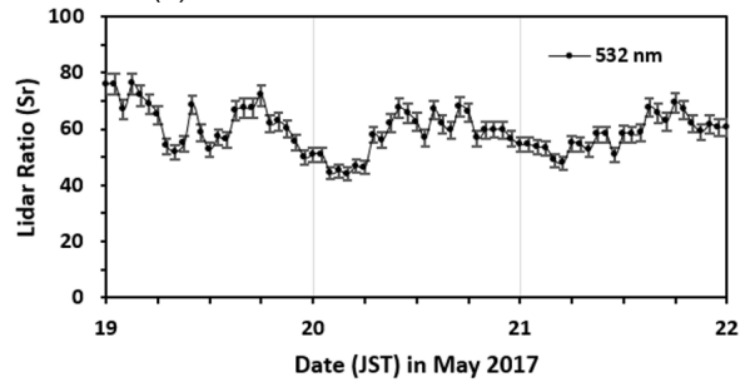

Fig. 3 Temporal change of lidar ratio in the case of (a) low RH observed during March 19-20, 2017 and (b) high RH observed during May 19-21, 2017. 

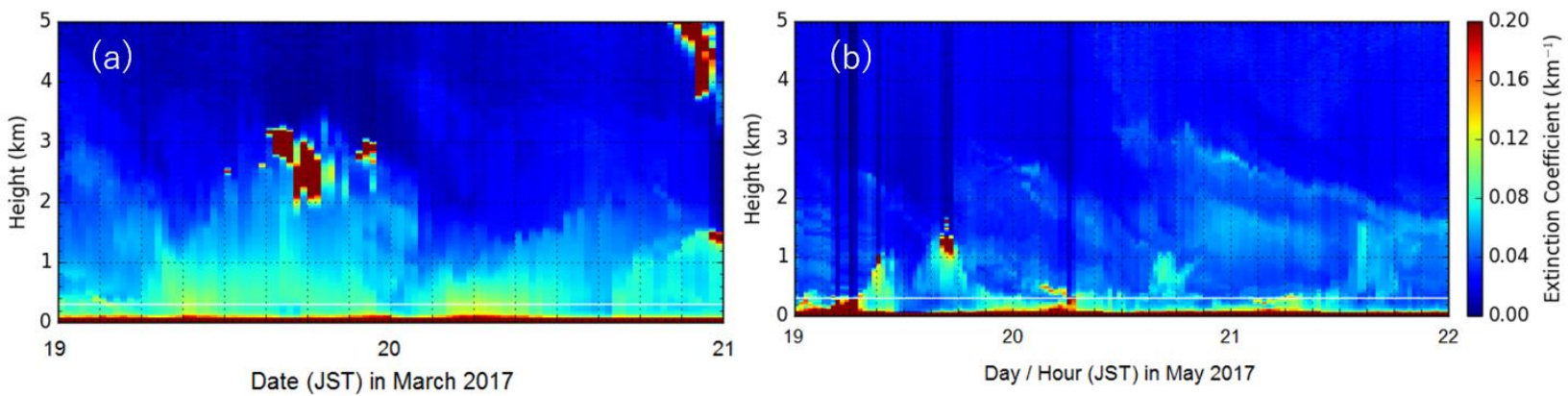

Fig. 4 Time-height indicator plot of the lidar data observed at $532 \mathrm{~nm}$ : (a) low RH case during March 19-20, 2017, and (b) high RH case during May 19-21, 2017.

Figures 4(a) and (b) show the time-height indicator plot of the AEC profile from the 532-nm observation data of the NIES lidar. In the May case with high RH, significant increase of AEC is seen in the morning of each day. This is caused by the increase in RH that leads to the onset of the $f(R H)$ effect in the atmosphere of Chiba City. Similar variation can also be seen in the surface data illustrated in Fig. 1(b). Another important feature seen in Fig. 4 is that continuous profiles are observed even when relatively thick clouds appear, and hence, far-end boundary values are not available from the lidar data. Obviously, this is the advantage of our approach in that the constraint of the AEC retrieval is imposed at the surface level by utilizing the data obtained from the ground-based instruments. This method will be useful for the detailed study of aerosol-cloud interaction occurring in the lower troposphere.

\section{ACKNOWLEDGEMENTS}

The first author (J.A.) would like to thank to Universitas Jenderal Soedirman, Chiba University, ICLAS, IRC, and ILRC29 Committee for supporting in ILCR 2019.

\section{REFERENCES}

[1] IPPC, "Climate Change 2007: The Physical Science Basis," Geneva-Switzerland, 2007.

[2] F. G. Fernald, "Analysis of atmospheric lidar observations: some comments.," Appl. Opt., vol. 23, no. 5, p. 652, 1984.

[3] H. Kuze, "Characterization of tropospheric aerosols by ground-based optical measurements," SPIE Newsroom, pp. 2-4, 2012.

[4] Y. Mabuchi, N. Manago, G. Bagtasa, H. Saitoh, N. Takeuchi, M. Yabuki, T. Shiina, and H. Kuze,
"Multi-wavelength lidar system for the characterization of tropospheric aerosols and clouds," in International Geoscience and Remote Sensing Symposium (IGARSS), 2012, pp. 25052508.

[5] H. Kinjo, H. Kuze, T. Takamura, M. Yabuki, and N. Takeuchi, "Determination of aerosol extinction-to-backscattering ratio from multiwavelength lidar observation," Jpn. J. Appl. Phys., 40(1), pp. 434-440, 2001.

[6] J. Aminuddin, S. Okude, N. Lagrosas, N. Manago, and H. Kuze, "Real time derivation of atmospheric aerosol optical properties by concurrent measurements of optical and sampling instruments," Open J. Air Pollut., vol. 07, no. 02, pp. 140-155, 2018.

[7] J. Aminuddin, B. Purbantoro, N. Lagrosas, N. Manago, and H. Kuze, "Landsat-8 satellite and plan position indicator lidar observations for retrieving aerosol optical properties in the lower troposphere," Adv. Remote Sens., vol. 07, no. 03, pp. 183-202, 2018.

[8] T. L. Anderson and J. A. Ogren, "Determining aerosol radiative properties using the TSI 3563 integrating nephelometer," Aerosol Sci. Technol., vol. 29 , no. 1, pp. 57-69, 1998.

[9] P. Zieger, R. Fierz-Schmidhauser, E. Weingartner, and U. Baltensperger, "Effects of relative humidity on aerosol light scattering: Results from different European sites," Atmos. Chem. Phys., vol. 13, no. 21, pp. 10609-10631, 2013.

[10] B. A. Bodhaine, N. B. Wood, E. G. Dutton, and J. R. Slusser, "On Rayleigh optical depth calculations," J. Atmos. Ocean. Technol., vol. 16, no. 11 PART 2, pp. 1854-1861, 1999.

[11] A. Shimizu, N. Sugimoto, and I. Matsui, "Detailed description of data processing system for lidar network in East Asia," in 25th International Laser Radar Conference, 2010, pp. 911-913. 